\title{
Microstructure and mechanical properties of $\mathrm{SiC}_{\mathrm{f}} / \mathrm{SiBCN}$ ceramic matrix composites
}

\author{
Jiaying WANG, Zhihua YANG, Xiaoming DUAN, Dechang JIA*, Yu ZHOU \\ Institute for Advanced Ceramics, Harbin Institute of Technology, Harbin 150080, China
}

Received: August 29, 2014; Accepted: September 17, 2014

(c) The Author(s) 2015. This article is published with open access at Springerlink.com

\begin{abstract}
SiC}$ fiber reinforced $\mathrm{SiBCN}$ ceramic matrix composites (CMCs) have been prepared by mechanical alloying and consolidated by hot pressing. During the sintering process, amorphous SiC fibers crystallized seriously and transformed into $\beta$-SiC. Meanwhile, the interfacial carbothermal reactions caused the strong bonding between the matrix and fibers. As a result, $\mathrm{SiC}_{\mathrm{f}} / \mathrm{SiBCN}$ fractured in a typical catastrophic manner. Room-temperature mechanical properties reached the maximums for the CMC samples sintered at $1900{ }^{\circ} \mathrm{C} / 60 \mathrm{MPa} / 30 \mathrm{~min}$. The density, flexural strength, Young's modulus and fracture toughness are $2.56 \pm 0.02 \mathrm{~g} / \mathrm{cm}^{3}, 284.3 \pm 17.9 \mathrm{MPa}, 183.5 \pm 11.1 \mathrm{GPa}$ and $2.78 \pm 0.14 \mathrm{MPa} \cdot \mathrm{m}^{1 / 2}$, respectively.
\end{abstract}

Keywords: hot pressing; composites; mechanical properties; fiber

\section{Introduction}

SiBCN ceramics have been widely investigated due to their better high-temperature properties such as oxidation [1-3] and creep resistance [4,5], which are expected to be applied in aerospace and anti-ablation structures in the future. Recently, various methods to fabricate these novel ceramics have been attempted such as precursor infiltration and pyrolysis (PIP) [6,7], physical vapor decomposition (PVD) [8,9] and mechanical alloying and hot pressing (MA-HP) [10]. However, a general problem of these ceramics is their brittleness, especially utilized under severe thermal shock or ablation environment. Thus, some approaches to reinforce the matrix such as the introduction of fibers are necessary.

Among the reinforcements for precursor derived ceramics, fibers have been widely used in

\footnotetext{
* Corresponding author.

E-mail: dcjia@hit.edu.cn
}

manufacturing the fiber reinforced ceramic matrix [11-14]. By the fiber/matrix debonding and fiber pull-out, elastic strain energy (or the stress field of the crack tip) could be dissipated in this kind of ceramic matrix composites (CMCs). Carbon fibers have usually been chosen as the reinforcements due to their outstanding high-temperature properties. Through the method of polymer impregnation pyrolysis, fiber reinforced ceramic composites could be fabricated by vacuum assisted infiltration of a liquid $\mathrm{SiBCN}$ precursor into stacked woven carbon fiber fabrics $[12,13]$. SiC particles are also utilized to improve the thermal stability of CMCs [15]. Unfortunately, carbon fibers could easily be oxidized in air atmosphere or oxygen contained ablative environment, which would steadily decrease the mechanical properties [16]. Mass ablation rate and linear ablation rate of $\mathrm{C}_{\mathrm{f}} / \mathrm{SiBCN}$ composites are namely $15.2 \mathrm{mg} / \mathrm{s}$ and $0.0455 \mathrm{~mm} / \mathrm{s}$ under an oxyacetylene torch environment respectively, which are notably more than those of $\mathrm{SiC}$ fiber reinforced composites [16]. To improve the ablation 
properties, silicon carbide fibers have been chosen as the reinforcement of $\mathrm{SiBCN}$ matrix in our recent research [17].

In this paper, $\mathrm{SiC}_{\mathrm{f}} / \mathrm{SiBCN} \mathrm{CMCs}$ have been prepared by mechanical alloying and hot pressing. Mechanical properties and microstructures of the CMCs were carefully studied, especially the behavior of carbon diffusion in the adjacent area of fibers. These results may be helpful for the choice of coating on $\mathrm{SiC}$ fibers and applications of fiber reinforced $\mathrm{SiBCN}$ composites.

\section{Experimental procedures}

\section{1 Amorphous SiBCN powder preparation}

Preparation of amorphous $\mathrm{SiBCN}$ powder has been discussed in our previous research $[18,19]$. Crystalline raw materials, namely cubic silicon $(45.0 \mu \mathrm{m}, 99.5 \%$ in purity, Beijing MounTain Technical Development Center, China), hexagonal boron nitride $(0.6 \mu \mathrm{m}$, $98.0 \%$ in purity, Advanced Technology \& Materials Co. Ltd., Beijing, China) and graphite powder $(8.7 \mu \mathrm{m}$, $99.5 \%$ in purity, Qingdao HuaTai Lubricant Sealing S\&T Co. Ltd., China) were used as starting materials in the experiment. The composition was designed as $\mathrm{Si}: \mathrm{C}: \mathrm{BN}=2: 3: 1$ in molar ratio. This designation depended on the literature and our previous research to compare with precursor derived ceramics [20]. The ball-to-powder mass ratio was set as 20:1. The powder mixture was loaded in silicon nitride vials along with silicon nitride balls under an argon atmosphere. Sealed with rubber rings, two vials were fixed on a planetary ball mill (Fritsch P4, Germany). The rotation speed of the main disk was set at $350 \mathrm{rpm}$ and the vials $600 \mathrm{rpm}$ in reverse, and the total milling time was $40 \mathrm{~h}$. The milling parameters have been discussed in another previous research paper [19].

\section{2 Fabrication of $\mathrm{SiC}_{\mathrm{f}} / \mathrm{SiBCN}$ ceramic composites by hot pressing method}

The properties of SiC fibers are summarized in Table 1. Before being cut into $1-2 \mathrm{~mm}$ in length, the fibers were treated to remove the organics on the surface

Table 1 Parameters of SLFC1 SiC fibers adopted in the current research

\begin{tabular}{|c|c|c|c|c|}
\hline Raw fiber & $\begin{array}{l}\text { Density } \\
\left(\mathrm{g} / \mathrm{cm}^{3}\right)\end{array}$ & $\begin{array}{c}\text { Fiber diameter } \\
(\mu \mathrm{m})\end{array}$ & $\begin{array}{c}\text { Tensile strength } \\
\text { (GPa) }\end{array}$ & $\begin{array}{c}\text { Young's modulus } \\
\text { (GPa) }\end{array}$ \\
\hline SLFC1 & 2.36 & $13 \pm 0.5$ & $1.5 \pm 1.0$ & $140 \pm 10$ \\
\hline
\end{tabular}

under $370{ }^{\circ} \mathrm{C} / 2 \mathrm{~h} /$ air. Then the powder and fibers were mixed with ethanol by ball milling for $4 \mathrm{~h}$. The mixture was dried and hot pressed in HIGH MULTI 1000 furnace. The mixture was heated to a set sintering temperature $\left(1800{ }^{\circ} \mathrm{C}\right.$ or $\left.1900{ }^{\circ} \mathrm{C}\right)$ under a heating rate of $20{ }^{\circ} \mathrm{C} / \mathrm{min}$, and then kept at the target temperature and pressure in the nitrogen atmosphere (1 bar) for $30 \mathrm{~min}$ or $60 \mathrm{~min}$. The loading process of the axial pressure started at $1200{ }^{\circ} \mathrm{C}$ and finished at $1400{ }^{\circ} \mathrm{C}$. During the cooling stage, the pressure was slowly unloaded in $5 \mathrm{~min}$. The sintering methods and serial numbers are listed in Table 2.

\section{3 Microstructure and property characterization}

For the phase identification, X-ray diffractometer $(40 \mathrm{kV} / 100 \mathrm{~mA}, \mathrm{D} / \max -\gamma \mathrm{B} \mathrm{Cu} \mathrm{K} \alpha$, Rigaku Corporation, Japan) was used to obtain the X-ray diffraction (XRD) spectra at $2 \theta=10^{\circ}-90^{\circ}$ with a scanning speed of $4\left(^{\circ}\right) / \mathrm{min}$. The as-milled SiBCN powder and fracture morphologies of the ceramics were observed by scanning electron microscopy (SEM, $30 \mathrm{kV}$, Quanta 200FEG, FEI Co., USA). The microstructure and energy dispersive X-ray spectroscopy (EDX) analysis were conducted on the transmission electron microscope (Tecnai G ${ }^{2}$ F30, $300 \mathrm{kV}$, FEI Co., USA).

The property measurement was carried out on omnipotence mechanics tester (Instron 5569, Instron Co., USA). Flexural strength and Young's modulus were obtained using three-point bending test on $3 \mathrm{~mm} \times$ $4 \mathrm{~mm} \times 32 \mathrm{~mm}$ bars with a span of $20 \mathrm{~mm}$ and a crosshead speed of $0.5 \mathrm{~mm} / \mathrm{min}$. Fracture toughness was tested on $2 \mathrm{~mm} \times 4 \mathrm{~mm} \times 20 \mathrm{~mm}$ bars with a span of $16 \mathrm{~mm}$ and a crosshead speed of $0.05 \mathrm{~mm} / \mathrm{min}$.

\section{Results and discussion}

\section{1 Characterizations of amorphous powder}

Crystalline raw powder has been completely decrystallized after $40 \mathrm{~h}$ milling from the XRD pattern as shown in Fig. 1. Through the crash between silicon

Table 2 Sintering method and serial number of $\mathrm{SiC}_{\mathrm{f}} / \mathrm{SiBCN}$ composite specimens

\begin{tabular}{cccc}
\hline \multirow{2}{*}{ Serial number } & \multicolumn{3}{c}{ Sintering method } \\
\cline { 2 - 4 } & $\begin{array}{c}\text { Sintering temperature } \\
\left({ }^{\circ} \mathrm{C}\right)\end{array}$ & $\begin{array}{c}\text { Pressure } \\
(\mathrm{MPa})\end{array}$ & $\begin{array}{c}\text { Holding time } \\
(\mathrm{min})\end{array}$ \\
\hline 180060 & 1800 & 60 & 30 \\
190040 & 1900 & 40 & 30 \\
19006030 & 1900 & 60 & 30 \\
19006060 & 1900 & 60 & 60 \\
\hline
\end{tabular}



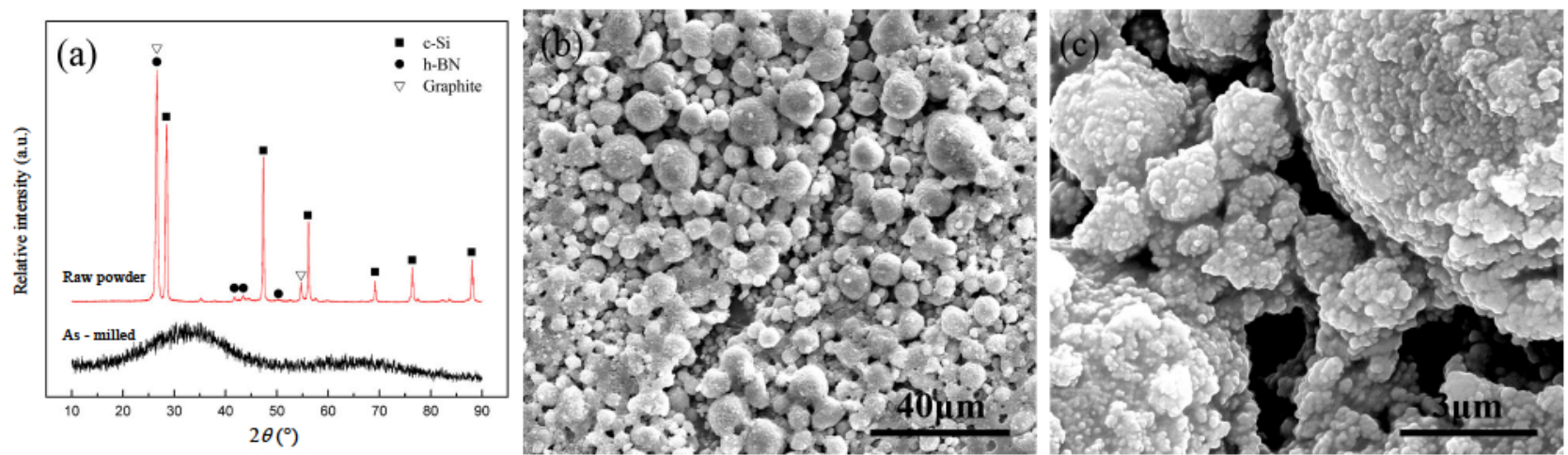

Fig. 1 (a) XRD analysis of raw powder mixture and as-milled amorphous SiBCN powder; (b) and (c) surface morphology of $\mathrm{SiBCN}$ powder by mechanical alloying process.

nitride vitals and balls, physical and chemical reactions including fierce collisions, rupture, local temperature, fusion and short-range collisions, happen during high-energy mechanical alloying. Meanwhile, in Fig. $1(\mathrm{~b})$, the amorphous powder is composed by numerous near-spherical agglomerates. In our previous research, these agglomerates are formed by nano particles, whose grain sizes are statistically $116 \pm 34 \mathrm{~nm}$ by transmission electron microscopy (TEM) analysis. More information about the amorphous powder, such as physical and surface characteristics, has been described in other research papers $[18,19]$.

\section{2 Microstructures of $\mathrm{SiC}_{\mathrm{f}} / \mathrm{SiBCN}$ composites}

After hot pressing, the mixture of short SiC fibers and $\mathrm{SiBCN}$ amorphous powder has crystallized seriously. The ceramic matrix consists of $\alpha$-SiC, $\beta$-SiC and $\mathrm{BNC}$ phases (Fig. 2). When the sintering temperature rises from $1800{ }^{\circ} \mathrm{C}$ to $1900{ }^{\circ} \mathrm{C}$, the diffraction peaks exhibit a reduced full width at half maximum (FWHM) and increased peak intensity, implying higher crystal content. Meanwhile, it reveals that $\beta$-SiC phase tends to transform to $\alpha$-SiC, according to the relative

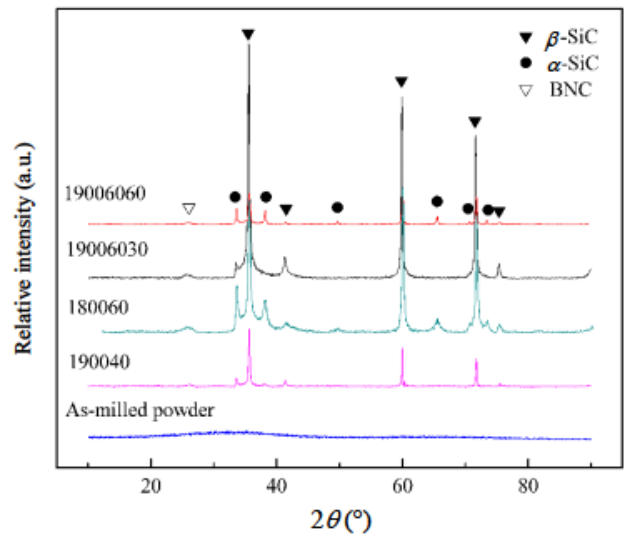

Fig. $2 \mathrm{XRD}$ analysis of $\mathrm{SiC}_{\mathrm{f}} / \mathrm{SiBCN}$ composites under different sintering conditions. intensities of $\mathrm{SiC}$ phases. Similar results are also obtained when the sintering pressure or holding time are further increased.

Figure 3(a) gives the TEM microstructures of the $\mathrm{SiC}_{\mathrm{f}} / \mathrm{SiBCN}$ matrix prepared at $1900{ }^{\circ} \mathrm{C} / 60 \mathrm{MPa} /$ $60 \mathrm{~min}$. The composite matrix mainly consists of nano-sized $\mathrm{SiC}$ and $\mathrm{BNC}$ grains. $\mathrm{SiC}$ grain size is about $100 \mathrm{~nm}$ as shown in Fig. 3(a). Meanwhile, BNC phases primarily distribute in the interphase of $\mathrm{SiC}$ grains and limit $\mathrm{SiC}$ grain growth [20]. However, it is difficult to observe the morphology of $\mathrm{SiC}$ fibers because the contrast of the composite matrix is similar with $\mathrm{SiC}$ fibers. Thanks to EDX spectrum, $\mathrm{SiC}$ fiber region is found in the composites sintered at $1800{ }^{\circ} \mathrm{C} /$ $60 \mathrm{MPa} / 30 \mathrm{~min}$. SiC fibers were severely crystallized and the size of $\mathrm{SiC}$ grain is about $100 \mathrm{~nm}$ after hot pressing (Figs. 3(b) and 3(c)).

Unfortunately, because the only difference between the matrix and fiber of bright field image is the existence of BNC interphase, the boundary between matrix and fiber is hard to be observed by TEM. More researches about the boundary would be reported in our further research.

\section{3 Interfacial carbothermal reactions in $\mathrm{SiC}_{\mathrm{f}} / \mathrm{SiBCN}$ composites during the sintering process}

Figure 4 indicates the fractured surface morphologies of $\mathrm{SiC}_{\mathrm{f}} / \mathrm{SiBCN}$ composites prepared at $1900{ }^{\circ} \mathrm{C} /$ $60 \mathrm{MPa} / 30 \mathrm{~min}$. Layer-fractured phenomenon of $\mathrm{SiC}$ fiber could be generally found in the fractured surface. Protrusions or pits exist in the center part of SiC fiber and the thickness of fractured layer is about $2 \mu \mathrm{m}$, which equals to the $\mathrm{SiC}$ sheath shown in Fig. 4(a). Meanwhile, on the fractured surface of composites prepared at $1900{ }^{\circ} \mathrm{C} / 60 \mathrm{MPa} / 60 \mathrm{~min}$, similar phenomenon could be observed as well but the 

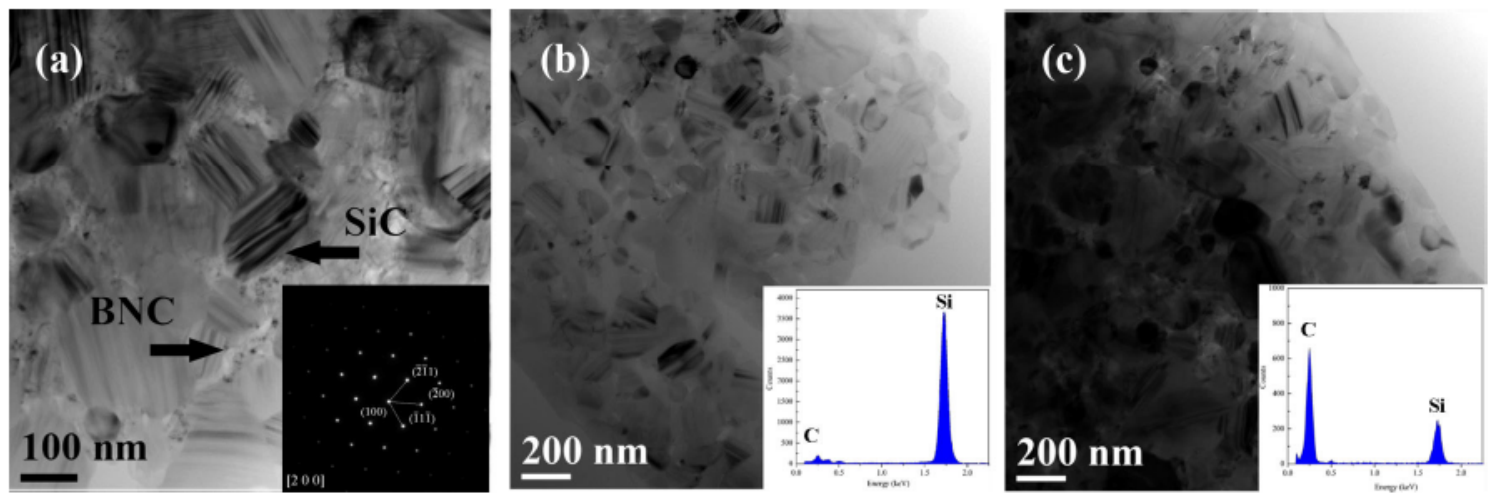

Fig. 3 (a) Bright field image and SAED pattern (inset) of $\mathrm{SiC}_{\mathrm{f}} / \mathrm{SiBCN} \mathrm{CMCs}$ prepared at $1900{ }^{\circ} \mathrm{C} / 60 \mathrm{MPa} / 60 \mathrm{~min}$; (b) and (c) microstructures and $\mathrm{EDX}$ analysis of $\mathrm{SiC}$ fibers in $\mathrm{SiC}_{\mathrm{f}} / \mathrm{SiBCN}$ composites prepared at $1800{ }^{\circ} \mathrm{C} / 60 \mathrm{MPa} / 30 \mathrm{~min}$ in different areas.

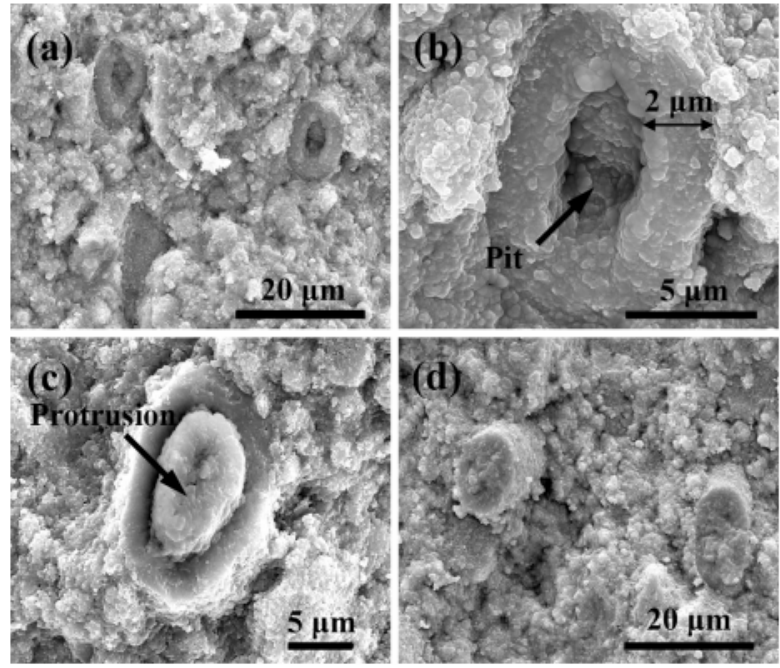

Fig. 4 Layer-fractured phenonemon in the $\mathrm{SiC}_{\mathrm{f}} / \mathrm{SiBCN}$ composites prepared at $1900{ }^{\circ} \mathrm{C} / 60 \mathrm{MPa} / 30 \mathrm{~min}$ and $60 \mathrm{~min}$ : (a) pits in the center of SiC fibers; (b) thickness of react layer; (c) protrusions in the center of SiC fibers; (d) morphology of fractured surface prepared at $1900{ }^{\circ} \mathrm{C} /$ $60 \mathrm{MPa} / 60 \mathrm{~min}$.

thickness increases and few protrusions or pits are left in the center area of the fiber. Between the edge and center of $\mathrm{SiC}$ fiber, there also exists a low-density layer.

Element analysis by line scanning around the fiber's adjacent area has been shown in Fig. 5. Three regions could be apparently observed from the outsides and insides, namely, $\mathrm{SiC}$ sheath, transition layer and center region. In the $\mathrm{SiC}$ sheath and center region, the content of carbon is significantly higher than that of transition layer. Meanwhile, the obvious carbon gradient exists in the fiber area. EDX spectra of fiber's different areas by TEM show the same result (Figs. 3(b) and 3(c)) as the line scanning analysis. Based on the results above, it can be inferred that chemical reactions happen during the sintering process and cause carbon diffusion in the adjacent area of fibers.
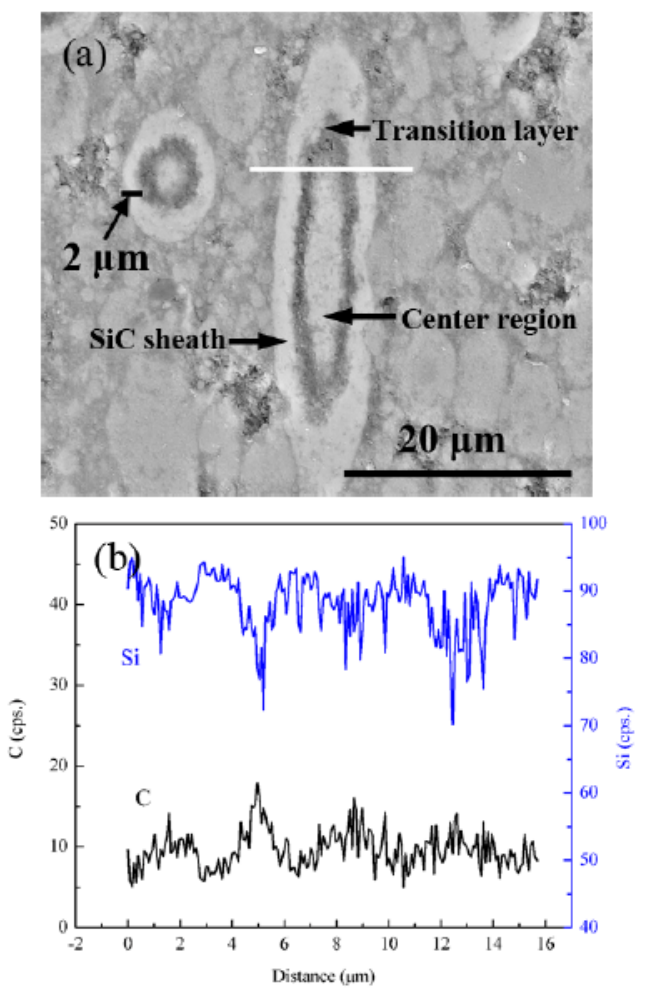

Fig. 5 Uniform distribution of carbon in the adjacent area of fibers: (a) electron back-scattered diffraction (EBSD) analysis of $\mathrm{SiC}_{\mathrm{f}} / \mathrm{SiBCN}$ composite surface; (b) line scanning in Fig. 5(a).

$\mathrm{SiC}_{x} \mathrm{O}_{y}$ and excess carbon in the $\mathrm{SiC}$ fibers and amorphous $\mathrm{SiBCN}$ powder are the main reason causing the carbon diffusion during the sintering process. SiC fibers applied in the experiments are similar with the first generation of Nicalon SiC fibers (Tokyo, Japan). During the curing process of fiber preparation, a large amount of oxygen $(\sim 1 \%)$ is introduced [21]. After the pyrolysis in the nitrogen atmosphere, fibers are composited of silicon, carbon and oxygen which form the amorphous $\mathrm{SiC}_{x} \mathrm{O}_{y}$ phase. Assisted by X-ray 
photoelectron spectroscopy (XPS) spectrum, the elemental and chemical analysis of fibers reflects that Nicalon fiber is a continuous $\mathrm{SiC}$ and $\mathrm{SiC}_{x} \mathrm{O}_{y}$ tetrahedron network with an excess of carbon and exhibits a silica sheath according to the $\mathrm{SiC}_{x} \mathrm{O}_{y}$ bonding at $102.5 \mathrm{eV}$ which is intermediate between $\mathrm{SiC}$ and $\mathrm{SiO}_{2}$ [22-25].

On the other hand, excess carbon, or free carbon, also influences interfacial microstructures between fibers and matrix. SiC fibers have been heat treated in $370{ }^{\circ} \mathrm{C}$ for $2 \mathrm{~h}$ to improve the dispersity of fibers in our research. The carbon in the out layer of fibers would react with oxygen and the content of free carbon decreases to cause $\mathrm{SiO}_{2}$ or $\mathrm{SiC}_{x} \mathrm{O}_{y}$ formed. Besides, free carbon also exists in amorphous $\mathrm{SiBCN}$ powder because the powder is fabricated by mechanical alloying and raw powder includes graphite. Related results have been reported in our other research paper [18]. Thus, free carbon in the fibers and powder would react with $\mathrm{SiO}_{2}$ and cause the strong bonding between fibers and matrix.

According to previous work and our analysis, we summarize the schematic of carbon diffusion and layer-fractured formation in Fig. 6. Carbon diffusion in the $\mathrm{SiC}_{\mathrm{f}} / \mathrm{SiBCN}$ ceramic composites is attributed to the carbothermal reactions between the free carbon and silica or silicon monoxide. The interfacial carbothermal reactions provide the diffusion drive and cause the gradient of carbon. In the first step from $1000{ }^{\circ} \mathrm{C}$ to $1500{ }^{\circ} \mathrm{C}$, the $\mathrm{SiC}_{x} \mathrm{O}_{y}$ phase would partly decompose to $\mathrm{SiC}$ and $\mathrm{SiO}_{2}$, and $\beta$-SiC crystals would be left during this process as shown in Fig. 6(b) [26]. When the sintering temperature rises to $1500{ }^{\circ} \mathrm{C}$, carbothermal reactions would happen and porous $\mathrm{SiC}$ transition layer would be formed on the surface of $\mathrm{SiC}$ fibers. If the temperature reaches above $1600{ }^{\circ} \mathrm{C}$, free carbon would react with the silicon monoxide produced by the decomposition of $\mathrm{SiC}_{x} \mathrm{O}_{y}$ phase and form the $\mathrm{SiC}$ sheath on the transition layer accompanying with the carbothermal reactions [27]. Possible reactions related to the gas formation are as follows:

$$
\begin{aligned}
& \mathrm{SiO}_{2}(\mathrm{~s})+3 \mathrm{C}(\mathrm{s}) \rightarrow \mathrm{SiC}(\mathrm{s})+2 \mathrm{CO}(\mathrm{g}) \\
& \mathrm{SiC}_{x} \mathrm{O}_{y}(\mathrm{~s}) \rightarrow \frac{x-y+1}{2} \mathrm{SiC}(\mathrm{s})+\frac{y-x+1}{2} \mathrm{SiO}(\mathrm{g}) \\
&+\frac{x+y-1}{2} \mathrm{CO}(\mathrm{g}) \\
& \mathrm{SiO}(\mathrm{g})+\mathrm{C}(\mathrm{s}) \rightarrow \mathrm{SiC}(\mathrm{s})+\mathrm{CO}(\mathrm{g}) \\
& 2 \mathrm{SiO}(\mathrm{g})+3 \mathrm{C}(\mathrm{s}) \rightarrow 2 \mathrm{SiC}(\mathrm{s})+\mathrm{CO}_{2}(\mathrm{~g})
\end{aligned}
$$

(a)

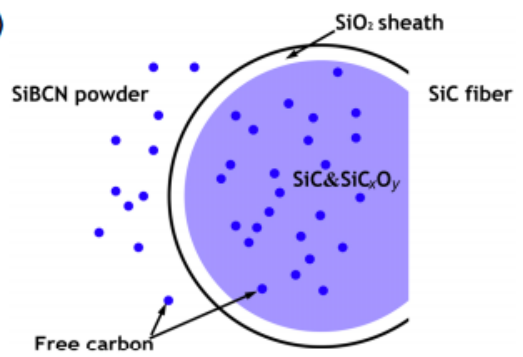

(b)

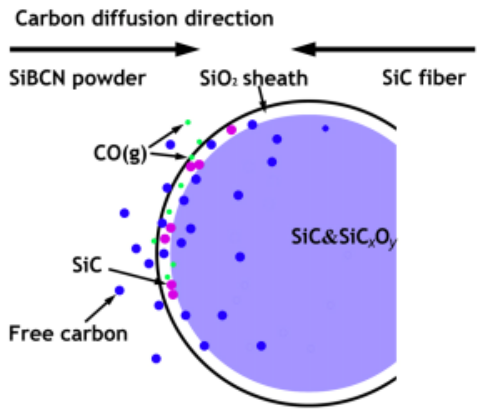

(c)

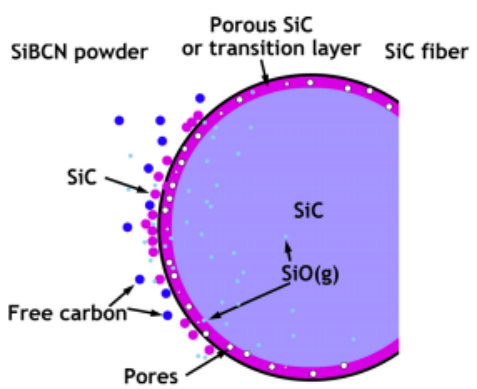

(d)

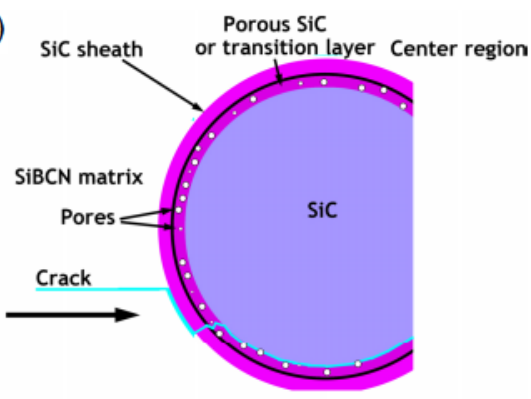

Fig. 6 Schematic of carbon diffusion and layer-fractured phenomenon in the $\mathrm{SiC}_{f} / \mathrm{SiBCN}$ composites.

The above reactions have been confirmed by experimental data and thermodynamics. The release of gas, such as $\mathrm{CO}, \mathrm{SiO}$ and $\mathrm{CO}_{2}$, causes the porous transition layer. Reactions (2), (3) and (4) are the reasons which obtain the formation of $\mathrm{SiC}$ sheath. The formation of $\mathrm{SiC}$ sheath and the calculation of thermodynamics could not indicate that the reactions could be possessed during the sintering process but prove the theory of re-deposition of $\mathrm{SiC}$ grains on the surface of SiC fibers as Honstein et al. proposed [27]. 


\section{4 Mechanical properties of $\mathrm{SiC}_{\mathrm{f}} / \mathrm{SiBCN}$ ceramic composites}

Figure 7 shows the typical fractured behavior of $\mathrm{SiC}_{\mathrm{f}} / \mathrm{SiBCN}$ ceramic composites. Unfortunately, the fractured behavior of composites is catastrophic brittle manner and the introduction of short SiC fibers could not change the fractured behavior due to $\mathrm{SiC}$ fiber crystallization and the strong interfacial bonding between $\mathrm{SiC}$ fibers and the matrix. When the crack propagates to $\mathrm{SiC}$ fibers, crack deflection cannot take place and it tends to directly cut through the interphase of $\mathrm{SiC}$ grains. These situations are also reflected from the fractured surface of three-point bending specimen as illustrated in Fig. 8. Except the specimen prepared at

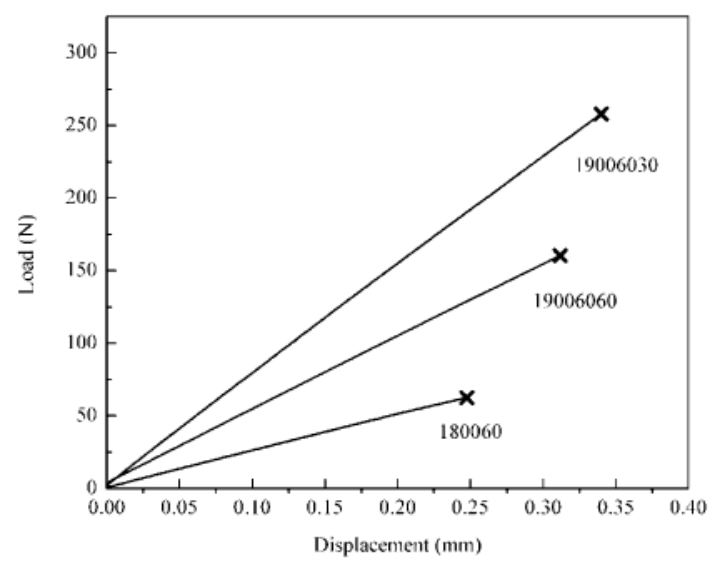

Fig. 7 Typical fractured behaviors of $\mathrm{SiC}_{\mathrm{f}} / \mathrm{SiBCN}$ composites at different sintering methods.
$1900{ }^{\circ} \mathrm{C} / 60 \mathrm{MPa} / 30 \mathrm{~min}$, no fiber pull-out could be observed on the fractured surfaces. Meanwhile, in the specimen prepared at $1900^{\circ} \mathrm{C} / 60 \mathrm{MPa} / 30 \mathrm{~min}$, the length of fiber pull-out is short so the toughening effect from the $\mathrm{SiC}$ fibers could not be insured. Further researches about BN weak layer have been surveyed in our other research paper in the future.

Table 3 summarizes the room-temperature mechanical properties and average thermal expansion coefficient of $\mathrm{SiC}_{\mathrm{f}} / \mathrm{SiBCN}$ ceramic composites. The average thermal expansion coefficient of $\mathrm{SiC}_{\mathrm{f}} / \mathrm{SiBCN}$ ceramic composites is slightly lower than that of the pure MA-SiBCN ceramic, whose thermal expansion coefficient is about $4.7 \times 10^{-6}\left({ }^{\circ} \mathrm{C}\right)^{-1}$. In the three-point bending fractured surface of specimen prepared at $1800{ }^{\circ} \mathrm{C} / 60 \mathrm{MPa} / 30 \mathrm{~min}$, the density of matrix is low and micro-defects in the matrix limit the mechanical properties of composites. With the increase of sintering parameters such as sintering temperature, pressure and holding time, the density of matrix improves notably and mechanical properties improve as well. Mechanical properties reach the maximum values after hot pressing at $1900{ }^{\circ} \mathrm{C} / 60 \mathrm{MPa} / 30 \mathrm{~min}$. The ceramic composite has room-temperature density, flexural strength, Young's modulus and fracture toughness of $2.56 \pm 0.02 \mathrm{~g} / \mathrm{cm}^{3}, \quad 284.3 \pm 17.9 \mathrm{MPa}, \quad 183.5 \pm 11.1 \mathrm{GPa}$ and $2.78 \pm 0.14 \mathrm{MPa} \cdot \mathrm{m}^{1 / 2}$, respectively. Compared with our previous research about carbon fiber reinforced $\mathrm{SiBCN}$ matrix, the mechanical properties improve
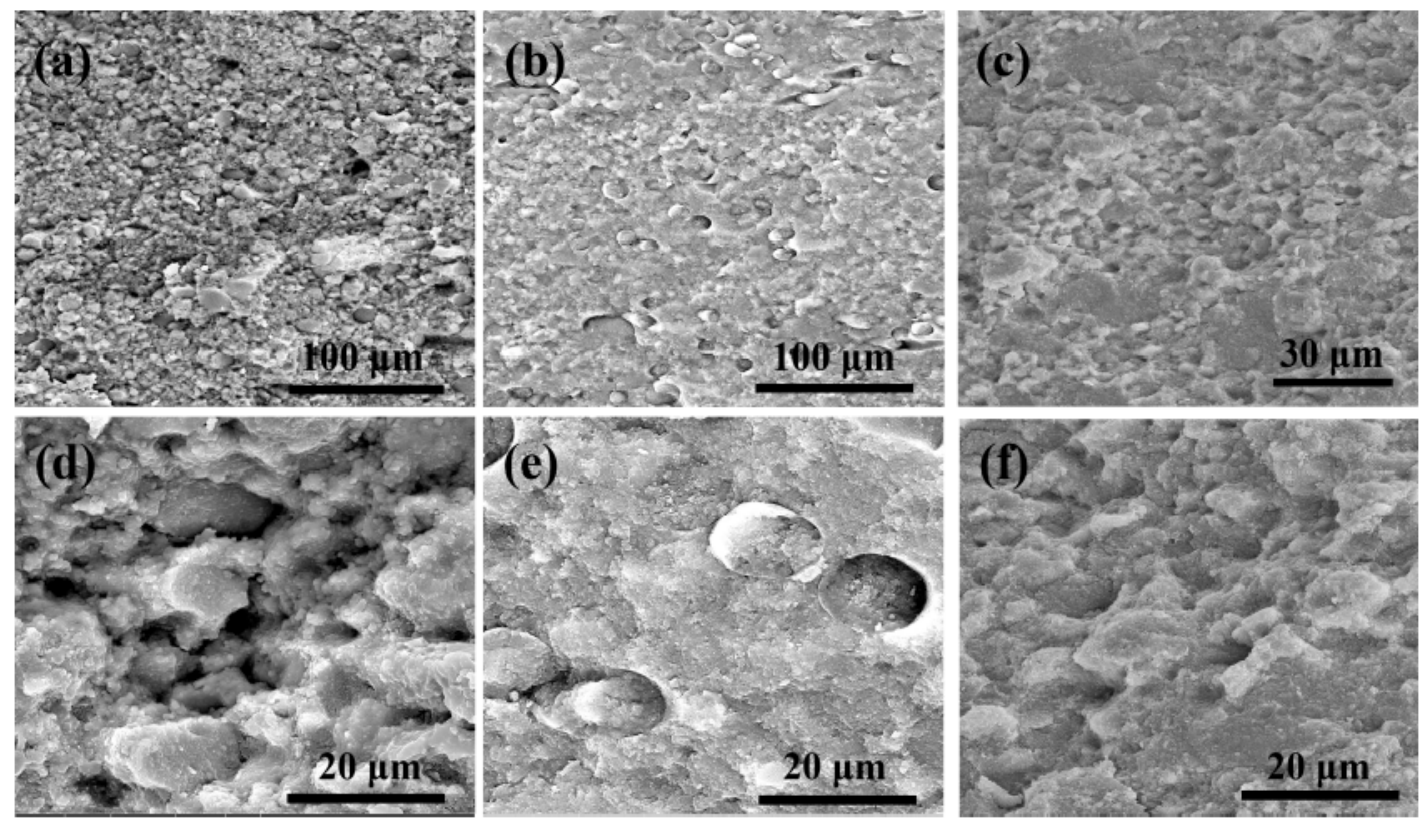

Fig. 8 Morphology of fractured surfaces of $\mathrm{SiC}_{\mathrm{f}} / \mathrm{SiBCN}$ composites prepared at different sintering methods: (a) and (d) $1800{ }^{\circ} \mathrm{C} / 60 \mathrm{MPa} / 30 \mathrm{~min}$; (b) and (e) $1900{ }^{\circ} \mathrm{C} / 60 \mathrm{MPa} / 30 \mathrm{~min}$; (c) and (f) $1900{ }^{\circ} \mathrm{C} / 60 \mathrm{MPa} / 60 \mathrm{~min}$. 
Table 3 Room-temperature properties of $\mathrm{SiC}_{\mathrm{f}} / \mathrm{SiBCN}$ composites hot pressed at different sintering methods

\begin{tabular}{ccccc}
\hline $\begin{array}{c}\text { Serial } \\
\text { number }\end{array}$ & $\begin{array}{c}\text { Density } \rho \\
\left(\mathrm{g} / \mathrm{cm}^{3}\right)\end{array}$ & $\begin{array}{c}\text { Flexural } \\
\text { strength } \\
\sigma(\mathrm{MPa})\end{array}$ & $\begin{array}{c}\text { Fracture } \\
\text { toughness } \\
K_{\mathrm{IC}} \\
\left(\mathrm{MPa} \cdot \mathrm{m}^{1 / 2}\right)\end{array}$ & $\begin{array}{c}\text { Young's } \\
\text { modulus } E \\
(\mathrm{GPa})\end{array}$ \\
\hline 180060 & $2.35 \pm 0.01$ & $73.3 \pm 2.4$ & $1.04 \pm 0.11$ & $73.3 \pm 3.0$ \\
190040 & $2.46 \pm 0.02$ & $70.2 \pm 6.3$ & $1.72 \pm 0.11$ & $64.1 \pm 2.8$ \\
19006030 & $2.56 \pm 0.02$ & $284.3 \pm 17.9$ & $2.78 \pm 0.14$ & $183.5 \pm 11.1$ \\
19006060 & $2.57 \pm 0.01$ & $171.8 \pm 6.5$ & $3.66 \pm 0.08$ & $107.3 \pm 7.3$ \\
\hline
\end{tabular}

notably. However, flexural strength of the specimen prepared at $1900{ }^{\circ} \mathrm{C} / 60 \mathrm{MPa} / 60 \mathrm{~min}$ is decreased compared with that prepared at $1900{ }^{\circ} \mathrm{C} / 60 \mathrm{MPa} /$ $30 \mathrm{~min}$ and fracture toughness is increased. On the fractured surface of the specimen prepared at $1900{ }^{\circ} \mathrm{C} /$ $60 \mathrm{MPa} / 60 \mathrm{~min}$, reactions between the matrix and fibers occur seriously and no fiber pull-out could be observed but some pits could be found. The size and shape of pits are different with SiC fiber pull-out pits, as shown in Fig. 8(f). Maybe $\mathrm{SiC}$ grains in the matrix grow with the holding time increasing. $\mathrm{SiC}$ grain pull-out could also improve the fracture toughness of $\mathrm{SiC}_{\mathrm{f}} / \mathrm{SiBCN}$ composites.

\section{5 Relations between interfacial carbothermal reactions and mechanical properties of $\mathrm{SiC}_{\mathrm{f}} / \mathrm{SiBCN}$ composites}

Apparently, interfacial carbothermal reactions decrease the mechanical properties of $\mathrm{SiC}_{\mathrm{f}} / \mathrm{SiBCN}$ composites at room temperature, especially the reinforcement of $\mathrm{SiC}$ fibers. The reactions between free carbon and $\mathrm{SiO}_{2}$ sheath of as-prepared $\mathrm{SiC}$ fibers would cause the strong bonding between the matrix and fibers. It makes the fibers hard to be debonded from the matrix when the composites are fractured. Meanwhile, the formation of porous transition layer is attributed to gases emitting such as $\mathrm{SiO}(\mathrm{g}), \mathrm{CO}(\mathrm{g})$ and $\mathrm{CO}_{2}(\mathrm{~g})$ during the sintering process. It also causes the degradation of $\mathrm{SiC}$ fibers. When the crack propagates through the $\mathrm{SiC}$ sheath, the crack could easily deflect in the transition layer and form the layer-fractured phenomenon.

Nowadays, similar results about the carbothermal reactions or porous layer between fibers and matrix during the sintering process have been investigated by other research groups as well. Layer-fractured phenomenon could be found in the $\mathrm{SiC}_{\mathrm{f}} / \mathrm{SiC}$ ceramic composites prepared by chemical vapor infiltration (CVI), in which SiC fibers have been coated by PIP-SiC [28]. Because of the weak bonding between CVI-SiC and PIP-SiC, the fractured surface of SiC also reflects the same phenomenon of these experiments.
Chen et al. [21] also pointed out that the oxygen picked up during the oxidation curing would influence the stoichiometry of sinter $\mathrm{SiC}$ fibers and the evolution of $\mathrm{CO}, \mathrm{CO}_{2}$ and $\mathrm{SiO}$ generates high porosity. Aluminum or $\mathrm{Al} / \mathrm{B}$ sintering additives have been introduced to the fibers as sintering additives improve the densification of fibers. To sum up, carbothermal reactions lead to the strong bonding and porosity layer between the matrix and fibers at the same time, which decrease the reinforcement of fibers.

To improve the properties of $\mathrm{SiC}_{\mathrm{f}} / \mathrm{SiBCN}$ composites, the methods to prevent the carbothermal reactions and ameliorate the bonding between matrix and fibers are necessary to be carried out. Other relative researches such as $\mathrm{BN}$ coating on the fiber to restrict the carbothermal reactions and improve the reinforcement of $\mathrm{SiC}$ fibers would be accomplished in our future research.

\section{Conclusions}

$\mathrm{SiC}_{\mathrm{f}} / \mathrm{SiBCN}$ ceramic composites were fabricated by hot pressing under different sintering conditions. Similar with the pure $\mathrm{SiBCN}$ matrix, the phases of $\mathrm{SiC}_{\mathrm{f}} / \mathrm{SiBCN}$ composite matrix are $\alpha$-SiC, $\beta$-SiC and $\mathrm{BNC}$ whose size is about $100 \mathrm{~nm}$. However, during the sintering process, $\mathrm{SiC}$ fibers crystallize seriously and degrade, which is not beneficial to their strengthening effects.

Carbothermal reactions during the sintering process cause the layer-fractured phenomenon and decrease the mechanical properties of $\mathrm{SiC}_{\mathrm{f}} / \mathrm{SiBCN}$ composites at room temperature. The excess carbon in the powder and fibers would react with $\mathrm{SiO}_{2}$ on the surface of fibers and the reaction layer mainly consists of $\mathrm{SiC}$ during the sintering process. The reactions would further cause the strong bonding between the matrix and fibers and make the composite fracture in a brittle manner. Meanwhile, with the release of gases such as $\mathrm{SiO}(\mathrm{g}), \mathrm{CO}(\mathrm{g})$ and $\mathrm{CO}_{2}(\mathrm{~g})$, micro defects in the transition layer would be left. When the crack spreads to the transition layer, it would slightly deflect in the layer and form the layer-fractured phenomenon in the fractured surfaces of specimens.

$\mathrm{SiC}_{\mathrm{f}} / \mathrm{SiBCN}$ composite prepared at $1900{ }^{\circ} \mathrm{C} / 60 \mathrm{MPa} /$ $30 \mathrm{~min}$ shows relatively excellent room-temperature mechanical properties, with the density, flexural strength, Young's modulus and fracture toughness of $2.56 \pm 0.02 \mathrm{~g} / \mathrm{cm}^{3}, \quad 284.3 \pm 17.9 \mathrm{MPa}, \quad 183.5 \pm 11.1 \mathrm{GPa}$ and $2.78 \pm 0.14 \mathrm{MPa} \cdot \mathrm{m}^{1 / 2}$, respectively. 


\section{Acknowledgements}

This work has been supported by the National Natural Science Funds for Distinguished Young Scholar of China under Grant No. 51225203. This work was also supported by the National Natural Science Foundation of China under Grant Nos. 51072041, 50902031 and 51021002. The authors also appreciated the meaningful comments from Dr. Pengfei Zhang.

Open Access: This article is distributed under the terms of the Creative Commons Attribution License which permits any use, distribution, and reproduction in any medium, provided the original author(s) and the source are credited.

\section{References}

[1] Colombo P, Mera G, Riedel R, et al. Polymer-derived ceramics: 40 years of research and innovation in advanced ceramics. J Am Ceram Soc 2010, 93: 1805-1837.

[2] Schiavon MA, Sorarù GD, Yoshida IVP. Poly (borosilazanes) as precursors of $\mathrm{Si}-\mathrm{B}-\mathrm{C}-\mathrm{N}$ glasses: Synthesis and high temperatures properties. $J$ Non-Cryst Solids 2004, 348: 156-161.

[3] Weinmann M, Schuhmacher J, Kummer H, et al. Synthesis and thermal behavior of novel $\mathrm{Si}-\mathrm{B}-\mathrm{C}-\mathrm{N}$ ceramic precursors. Chem Mater 2000, 12: 623-632.

[4] Christ M, Thurn G, Weinmann M, et al. High-temperature mechanical properties of $\mathrm{Si}-\mathrm{B}-\mathrm{C}-\mathrm{N}$-precursor-derived amorphous ceramics and the applicability of deformation models developed for metallic glasses. J Am Ceram Soc 2000, 83: 3025-3032.

[5] Kumar NVR, Prinz S, Cai Y, et al. Crystallization and creep behavior of Si-B-C-N ceramics. Acta Mater 2005, 53: 4567-4578.

[6] Riedel R, Ruswisch LM, An LN, et al. Amorphous silicoboron carbonitride ceramic with very high viscosity at temperatures above $1500{ }^{\circ} \mathrm{C} . \mathrm{J} \mathrm{Am}$ Ceram Soc 1998, 81: 3341-3344.

[7] Widgeon S, Mera G, Gao Y, et al. Effect of precursor on speciation and nanostructure of SiBCN polymer-derived ceramics. J Am Ceram Soc 2013, 96: 1651-1659.

[8] Vijayakumar A, Todi RM, Sundaram KB. Effect of $\mathrm{N}_{2} / \mathrm{Ar}$ gas mixture composition on the chemistry of SiCBN thin films prepared by RF reactive sputtering. $J$ Electrochem Soc 2007, 154: H271-H274.

[9] Vishnyakov VM, Ehiasarian AP, Vishnyakov VV, et al. Amorphous boron containing silicon carbo-nitrides created by ion sputtering. Surf Coat Technol 2011, 206: 149-154.

[10] Yang Z-H, Zhou Y, Jia D-C, et al. Microstructures and properties of $\mathrm{SiB}_{0.5} \mathrm{C}_{1.5} \mathrm{~N}_{0.5}$ ceramics consolidated by mechanical alloying and hot pressing. Mat Sci Eng A 2008, 489: $187-192$.

[11] Weinmann M, Kamphowe TW, Schuhmacher J, et al. Design of polymeric Si-B-C-N ceramic precursors for application in fiber-reinforced composite materials. Chem Mater 2000, 12: 2112-2122.

[12] Lee SH, Weinmann M, Aldinger F. Processing and properties of $\mathrm{C} / \mathrm{Si}-\mathrm{B}-\mathrm{C}-\mathrm{N}$ fiber-reinforced ceramic matrix composites prepared by precursor impregnation and pyrolysis. Acta Mater 2008, 56: 1529-1538.

[13] Lee $\mathrm{S}-\mathrm{H}$, Weinmann $\mathrm{M} . \mathrm{C}_{\text {fiber }} / \mathrm{SiC}$ filler $/ \mathrm{Si}-\mathrm{B}-\mathrm{C}-\mathrm{N}_{\text {matrix }}$ composites with extremely high thermal stability. Acta Mater 2009, 57: 4374-4381.

[14] Lee S-H, Weinmann M, Aldinger F. Fabrication of fiber-reinforced ceramic composites by the modified slurry infiltration technique. $J$ Am Ceram Soc 2007, 90: $2657-2660$.

[15] Lee S-H, Weinmann M, Gerstel P, et al. Extraordinary thermal stability of $\mathrm{SiC}$ particulate-reinforced polymerderived Si-B-C-N composites. Scripta Mater 2008, 59: 607-610.

[16] Zhang P, Jia D, Yang Z, et al. Progress of a novel non-oxide $\mathrm{Si}-\mathrm{B}-\mathrm{C}-\mathrm{N}$ ceramic and its matrix composites. $J$ Adv Ceram 2012, 1: 157-178.

[17] Wang J, Duan X, Yang Z, et al. Ablation mechanism and properties of $\mathrm{SiC}_{\mathrm{f}} / \mathrm{SiBCN}$ ceramic composites under an oxyacetylene torch environment. Corros Sci 2014, 82: 101-107.

[18] Zhang P, Jia D, Yang Z, et al. Physical and surface characteristics of the mechanically alloyed $\mathrm{SiBCN}$ powder. Ceram Int 2012, 38: 6399-6404.

[19] Zhang P, Jia D, Yang Z, et al. Influence of ball milling parameters on the structure of the mechanically alloyed SiBCN powder. Ceram Int 2013, 39: 1963-1969.

[20] Zhang P, Jia D, Yang Z, et al. Crystallization and microstructural evolution process from the mechanically alloyed amorphous $\mathrm{SiBCN}$ powder to the hot-pressed nano SiC/BN(C) ceramic. J Mater Sci 2012, 47: 7291-7304.

[21] Chen L, Zhang L, Cai Z, et al. Effects of oxidation curing and sintering additives on the formation of polymerderived near-stoichiometric silicon carbide fibers. $\mathrm{J} \mathrm{Am}$ Ceram Soc 2008, 91: 428-436.

[22] Schreck P, Vix-Guterl C, Ehrburger P, et al. Reactivity and molecular structure of silicon carbide fibres derived from polycarbosilanes. J Mater Sci 1992, 27: 4237-4242.

[23] Schreck P, Vix-Gguterl C, Ehrburger P, et al. Reactivity and molecular structure of silicon carbide fibres derived from polycarbosilanes. J Mater Sci 1992, 27: 4243-4246.

[24] Ponthieu C, Marhic C, Lancin M, et al. SIMS, EDX, EELS, AES, XPS study of interphases in nicalon fibre-LAS glass matrix composites II. J Mater Sci 1994, 29: 4535-4544.

[25] Lancin M, Ponthieu C, Marhic C, et al. SIMS, EDX, EELS, AES, XPS study of interphases in nicalon fibre-LAS glass matrix composites I. J Mater Sci 1994, 29: 3759-3766.

[26] Bois L, Maquet J, Babonneau F, et al. Structural characterization of sol-gel derived oxycarbide glasses. 2 . Study of the thermal stability of the silicon oxycarbide phase. Chem Mater 1995, 7: 975-981.

[27] Honstein G, Chatillon C, Baillet F. Thermodynamic approach to the vaporization and growth phenomena of $\mathrm{SiC}$ ceramics. I. $\mathrm{SiC}$ and $\mathrm{SiC}-\mathrm{SiO}_{2}$ mixtures under neutral conditions. J Eur Ceram Soc 2012, 32: 1117-1135.

[28] Ding D, Zhou W, Luo F, et al. Mechanical properties and oxidation resistance of $\mathrm{SiC}_{\mathrm{f}} / \mathrm{CVI}-\mathrm{SiC}$ composites with PIP-SiC interphase. Ceram Int 2012, 38: 3929-3934. 